\title{
Cooperation, competition, and interpersonal attitudes in small groups'
}

ROBERT B. ZAJONC AND IRWIN C. MARIN THE UNIVERSITY OF MICHIGAN

Previous theorizing maintains that interpersonal attitudes of cooperating and competing individuals are primarily a function of the antecedent motivational interdependence that characterizes these relations. The present experiment sought to establish if outcomes, rather than motivational antecedents, of cooperation and competition are a sufficient condition of the resultant interpersonal attitudes. Two-man teams played a non-zero sum game, in which one member of each team always increased the likelihood of his team's success, while the other always decreased it. Successful members were found to have more favorable attitudes toward their opponents than toward their teammates. The opposite results were obtained for unsuccessful members. While the evidence for the dependence of interpersonal attitudes upon the outcomes of cooperation and competition was clear, no support was found for the hypothesis that interpersonal attitudes also depend on antec edent motivational interdependence.

According to the classical theory (Deutsch, 1949), cooperative relations are characterized by promotive interdependence, whereby the individuals involved mutually facilitate their goal attainment. Cooperation therefore enhances interpersonal attraction. Contrient interdependence, which is the defining property of competition, prevents goal attainment, and hence becomes a source of interpersonal hostility. It is commonly thought that this interdependence is in itself a sufficient source of interpersonal attitudes. The cooperative situation brings out the "membership motive" (Deutsch, 1949, pp. 133ff), which generates cohesive forces among members, promotes affiliative behavior, and fosters loyalty. Competition, however, by accentuating mutual goal blocking, promotes outgroup attitudes that are often negative.

The concepts of "promotive" and "contrient" interdependence may be somewhat misleading for, in fact, cooperating individuals promote their mutual goal attainment only as long as they are making some progress toward that goal. Poor performance of one team member has obstructive consequences for the entire team. Conversely, competition blocks goal attainment only if one is confronted by a more skilful opponent. The conditions of cooperation and of competition are, therefore, perhaps more conveniently described in terms of reinforcement contingencies. Given two individuals or groups, $X$ and $Y$, in the case of cooperation the reinforcement of $X$ is positively correlated with the quality of $Y$ 's performance, and the reinforcement of $Y$ is positively correlated with $X ' s$ performance. In the case of competition these correlations are negative (Zajonc, 1966).
If goal facilitation leads to attraction and blocking to hostility, then these attitudes may depend less on the nature of the interpersonal relations in cooperation and competition, than on their outcomes. That is, if $X$ actually facilitates $Y$ 's goal attainment, $Y$ will have positive attitudes toward $X$ regardless of whether he cooperates with $X$ or competes against him (Berkowitz \& Levy, 1956). And if X blocks Y's goal, independently of the nature of his relationship to $\mathrm{X}, \mathrm{Y}$ should develop some hostility toward $\mathrm{X}$ (Rosenthal \& Cofer, 1948). The question examined in this paper is whether the outcomes of cooperative and competitive interpersonal relations can alone account for the resultant interpersonal attitudes.

\section{Method}

Sixteen University of Michigan students, paid $\$ 1.25$ per hour, participated in what they thought were two experiments. Experiment "I" was conducted in the form of a non-zero sum game involving two two-man teams. The game was played in pairs, alternating from trial to trial, with just one and always the same member of one team opposing just one and always the same member of the other team. The apparatus consisted of four panels, two for each team, equipped with a warning signal, a stimulus light, a red "failure" light, and a reaction time switch. On any given trial, following a warning signal, the designated pair of players would attempt, as quickly as possible, to turn off stimulus lights on their respective panels. Ostensibly, the "slower" of the two RTs was immediately followed by a red "failure" light. All outcomes were programmed and, without Ss' knowledge, individual successes and failures were independent of actual performance. The game consisted of 60 trials, with one team member of each team participating in the 30 odd trials, and the other member in the 30 even trials.

The stated objective was for a team as a whole to score at least 40 points, and thus qualify for a $\$ 10.00$ prize. A point was scored when a team member showed a faster reaction time than his opponent. Since one player alone was unable to amass a total of 40 points required to win the $\$ 10.00$ prize, an interdependence existed between the teammates. The outcomes were so programmed, however, that each team had a "winner" who was successful on 24 trials and a "loser" who was successful on six trials. Of course, the "winner" of a given team always played against the "loser" of the other team.

In Experiment "II," interpersonal attitude measures were adminstered to each $\mathrm{S}$ in isolation from the others. 
Table 1. Attitudes of Winners and Losers

Toward Their Teammates and Opponents

\begin{tabular}{clllll} 
Object of attifude & \multicolumn{2}{c}{ Winners } & \multicolumn{2}{c}{ Losers } \\
& $x^{\text {SD }}$ & $x^{\text {SD }}$ & SD \\
\hline Complete adjective list: & & & & \\
Toward Teammate & $2.49 *$ & .39 & 3.06 & .61 \\
Toward Opponent & 3.32 & .38 & 2.78 & .61 \\
Partial adjective list: & & & & \\
Toward Teammate & 2.37 & .87 & 3.30 & .96 \\
Toward Opponent & 3.59 & .91 & 2.76 & 1.10 \\
\hline
\end{tabular}

*-6 scale with 0 as the positive end point.

The attitude test was composed of 100 adjectives previously rated for "likeability" (Anderson, 1964). For each adjective Ss indicated whether it more accurately described his teammate or his opponent. The attitude score of a given $S$ toward his teammate consisted of the "likeability" scores averaged over all those traits which he rated to be more characteristic of his teammate than of his opponent. His attitude toward his opponent was computed in a similar fashion.

\section{Results and Discussion}

If we designate the score of the "winner" by $\mathrm{W}$ and that of the "loser" by $L$, and if we denote by $T$ that the teammate is being rated and by $O$ that the opponent is being rated, then the hypothesis which emphasizes the antecendents of cooperation and competition predicts the inequality $(W T+L T)>(W O+L O)$. The hypothesis which stresses the consequences of cooperation and competition, on the other hand, predicts $(\mathrm{WO}+\mathrm{LT})>(\mathrm{WT}+\mathrm{LO})$. When WT and WO are held constant, both hypotheses predict LT $>$ LO. But the two hypotheses make diametrically opposed predictions for the winners. Table 1 shows the mean attitude scores of winners and losers rating their teammates and their opponents. It is clear from these results (first two rows of Table 1 ) that these interpersonal attitudes are influenced primarily by the outcomes of the interpersonal relations rather than by their antecedents. The relevant interaction term was significant at the .05 level $(F=4.76, d f=1 / 12)$. Pooling across winners and losers, the attitudes toward opponents were somewhat more favorable than toward teammates, although this main effect failed to reach an acceptable significance level.

The above results cannot be interpreted by assuming that the Ss inferred a difference in skill between their opponents and teammates, for the apparent performance was the same for both. Winners rated a teammate who won 20\% of the time and an opponent who also won $20 \%$ of the time. Losers rated a teammate and an opponent who both scored a point on $80 \%$ of the trials. To minimize the effects of apparent skill further, all task-related adjectives were removed from the list, and two samples of 15 were drawn, one from the most favorable quartile and another from the least favorable quartile. Using only these 30 adjectives, attitude scores were computed as before, and they are shown in the third and fourth rows of Table 1. It is clear that the previous results are confirmed, the analysis of variance showing an $F=5.24(d f=1 / 12, p<.05)$ for the relevant interaction term, with $39.7 \%$ of the variance accounted for.

While the above results show no attitudinal effects that could be attributed to the antecedents of cooperation and competition, the present experiment, to be sure, dealt with a minimal social situation. The Ss' relations to one another were fleeting, they were arbitrarily established by the experimenter, and did not commit the individuals in any particular way. But the classical theory holds that just by virtue of the particular goal interdependence present in cooperation and competition the attitudes of individuals who cooperate with each other will be more favorable than that of those who compete with eachother (Deutsch, 1949, pp. 138-139, 145-147). The theory implies that interpersonal attitudes are influenced more by the perceived intentions of the teammates' and opponents' actions than by the outcomes of these actions.

No doubt, if the interpersonal relations involved were more permanent or more pervasive, different results might have been obtained. However, if there was greater team-commitment on the part of the participants, and if, for example, they were given a choice in selecting their partners, entirely new factors would come into play. In the event of choice, for example, the effects of post-decision dissonance would come into play, and we would expect attitudes toward losing teammates to be more favorable than toward losing opponents.

\section{References}

Anderson, N. H. Likeableness ratings of 555 personality trait adjectives. Los Angeles: University of California (mimeo), 1964.

Berkowitz, L., \& Levy, B. I. Pride in group performance and grouptask motivation. J. abnorm. soc. Psychol., 1956, 53, 300-306. Deutsch, M. A theory of cooperation and competition. Hum, Relat. $1949,2,129-152$

Rosenthal, D., \& Cofer, C. N. The effect on group performance of an indifferent and neglectful attitude shown by one group member. J. exp. Psychol., 1948, 38, 568-577.

Zajonc, R. B. Social psychology: An experimental approach. Belmont, Calif., Wadsworth, 1966.

\section{Note}

1. This research was supported by the Office of Naval Research, Contract Nonr-1224(34) NR 170-309. 